\title{
CAPACITAÇÃO DE MOTORISTAS DE CAMINHÕES-TANQUE EM AMBIENTES NÃO FORMAIS NO SISTEMA PETROBRAS DO ESTADO DE SANTA CATARINA
}

\author{
Fábio Lopes; Nilo Otani \\ E-mail: mtc.lopes@gmail.com; nilo.otani@ifsc.edu.br \\ Instituto Federal de Educação, Ciência e Tecnologia de Santa Catarina \\ DOI: $10.15628 /$ rbept.2020.9798
}

Artigo submetido em mar./2020 e aceito em abr./2020

\begin{abstract}
RESUMO
Este artigo tem como objetivo compreender o desenvolvimento da transmissão de conhecimentos sobre o processo de trabalho entre motoristas de caminhões-tanque. Tratouse de uma pesquisa aplicada de análise qualitativa. A coleta de dados foi realizada em uma plataforma de carregamento de combustíveis localizada no munícipio de Biguaçu (SC), afim de elucidar as principais dificuldades de aprendizagem, proporcionando um norte para a elaboração de um recurso educacional vivo, orgânico e estruturado com base nas principais dúvidas dos trabalhadores, sendo confeccionado com base em Histórias em Quadrinhos (HQ) e do próprio conceito de Microlearning.
\end{abstract}

Palavras-Chave: Ambientes não formais. Motoristas de caminhão-tanque. Comunidades de prática. Microlearning.

\section{TRAINING OF TANK TRUCK DRIVERS IN NON-FORMAL ENVIRONMENTS IN THE PETROBRAS SYSTEM IN THE STATE OF SANTA CATARINA}

\begin{abstract}
This article aims to understand the development of knowledge transmission about the work process among tank truck drivers. It was an applied research of qualitative analysis. Data collection was carried out on a fuel loading platform located in the municipality of Biguaçu (SC), in order to elucidate the main learning difficulties, providing a guide for the development of a living, organic and structured educational resource based on the main doubts of workers, being made based on Comics (HQ) and the very concept of Microlearning.
\end{abstract}

Keywords: Non-formal environments. Tank truck drivers. Communities of practice. Microlearning 


\section{INTRODUÇÃO}

Historicamente os centros de formação tradicionais são os responsáveis pela elaboração pedagógica e formação profissional dos mais variados grupos de indivíduos que compõem nossa sociedade. Entretanto, o mundo laboral, por si só, forma os indivíduos pelo ato do trabalho, no qual as gerações mais experientes condicionam a transmissão de conhecimentos através da prática diária e do ato laborativo em si.

No processo de trabalho como um todo, o indivíduo torna-se professor e aluno de seus pares, em um contínuo processo de transmissão de conhecimentos, donde ocorre a união entre o trabalho, a educação e o ensino. Um olhar reflexivo sobre o mundo do labor nos permite compreender que a formação destes indivíduos (inseridos no mundo do trabalho e em seus processos) não se situa somente em ambientes formais de capacitação. A formação humana integral poderá ser observada nos mais variados ambientes de trabalho situados no mundo real. Nessa perspectiva, aborda-se a capacitação de um grupo específico de indivíduos que trabalham em uma área industrial situada em um ambiente não formal de capacitação/formação na base de distribuição da Petrobras Transportes (Transpetro), no município de Biguaçu (SC).

O transporte de combustíveis realizado em solo brasileiro apresenta um modal bem característico, visto que é realizado através de caminhões-tanque, abastecendo sua região de influência econômica. Tal atividade é realizada por profissionais da estrada, os ditos caminhoneiros, que sofrem várias interferências de ordem social e psicológica, o que acaba afetando seu desempenho no trabalho. (GÂNDARA; CRUZ, 2019).

A capacitação destes profissionais no próprio ambiente de trabalho constitui, nos chamados ambientes não formais de aprendizagem, um dos arcabouços da união entre $\mathrm{o}$ fator trabalho e o fator aprendizagem. $O$ caminhoneiro aprende, trabalha e retransmite conhecimento através de suas atividades cotidianas. (GOHN, 2006).

$\mathrm{Na}$ visão proposta por Wenger (2011), esta troca de aprendizados no mundo laboral constitui uma tríade para formação e transmissão dos conhecimentos gerados em um local específico, o próprio local de trabalho. Esta tríade é formada pela união do domínio, da comunidade envolvida e da própria técnica empregada para a resolução de um determinado problema.

O grupo de caminhoneiros que compôs este estudo apresentava todas as características de uma comunidade de práticas, pois todos os elementos formadores estavam presentes. Destaca-se o elemento técnica, que é desenvolvido durante e ao longo de todo o processo de trabalho realizado por estes profissionais. Para Vieira Pinto (2008), a técnica e o trabalho, juntamente com a concepção de humanidade, compõem os alicerces estruturais para a formação da intelectualidade humana. 
O processo em que um indivíduo ajuda o outro na aprendizagem e na realização de seu trabalho, em um ambiente dito não oficial de formação, compõe o que chamamos de ambientes não formais de aprendizagem ou ambiente não formal de formação. (GOHN, 2015).

O fator aprendizagem, e suas principais dificuldades no processo de aquisição de conhecimentos, foi o eixo norteador para a elaboração de um questionário, distribuído entre 30 participantes da pesquisa, todos caminhoneiros que trabalham no transporte logístico de combustíveis para a região da Grande Florianópolis. No questionário realizamos uma série de perguntas sobre as dificuldades de aprendizagem no modelo atual de distribuição de trabalho, coletando dados demográficos tais como tempo de experiência na profissão, bem como a indicação de um produto educacional que pudesse ajudá-los na elucidação de suas dúvidas mais comuns.

O conceito e a criação de um avatar, uma figura criada e baseada em uma história em quadrinhos, estruturada na figura do próprio caminhoneiro, foi a estratégia utilizada para propor um recurso educacional baseado em um programa de 4 semanas, em uma cartilha digital que era continuamente apresentada para todos em uma tela virtual.

A caracterização do avatar, seus trajes e sua fisionomia foram baseados na figura média do caminhoneiro que atua na plataforma de carregamento.

$O$ recurso educacional foi baseado no modelo de aprendizagem tipo Microlearning, em que pequenas doses de conhecimentos eram inseridas no cotidiano diário do caminhoneiro, que consumia o recurso educacional enquanto esperava o seu tempo para carregamento dos caminhões. (ALVES; ANDRÉ; 2020). No material tínhamos assuntos diversos, tais como a importância do uso de Equipamentos de Proteção Individual (EPl's), ergonomia, segurança no trabalho, educação de trânsito, manutenção veicular e alimentação saudável.

O problema investigado com a presente pesquisa estava relacionado com a transmissão de conhecimentos no processo de trabalho entre os motoristas de caminhão-tanque em um típico ambiente não formal de capacitação/formação (Estação de Carregamento Rodoviário da Transpetro em Biguaçu/SC).

Buscou-se responder à seguinte pergunta de pesquisa: "Como se realiza o processo de aquisição de conhecimentos pelos motoristas de caminhão-tanque em um ambiente não formal de aprendizagem do sistema Petrobras?"

Para responder à pergunta de pesquisa, definiu-se como objetivo geral compreender o desenvolvimento de transmissão de conhecimento sobre o processo de trabalho entre os motoristas de caminhões-tanque que operam no Estado de Santa Catarina (SC) e formular uma cartilha educacional através da revisão da literatura, que facilite a absorção dos principais conceitos envolvidos no processo de trabalho. 


\section{METODOLOGIA}

Do ponto de vista dos seus objetivos, trata-se de uma Pesquisa Descritiva, que enumera as caraterísticas de um determinado grupo social ou um determinado fenômeno específico. (GIL, 1999).

No caso em tela, analisaremos uma comunidade de práticas laborais específica, em seu próprio local de trabalho, observando e realizando perguntas (através de questionários) acerca da transmissão do conhecimento de todo o processo de trabalho realizado.

Quanto aos procedimentos, trata-se de uma Pesquisa Participante, em que ocorre o envolvimento do pesquisador com os membros da situação pesquisada; a colaboração e a integração entre os sujeitos da pesquisa e o pesquisador são de suma importância para este tipo de estudo, visto que o pesquisador deverá adentrar no mundo dos seus pesquisados. (SILVA; GRIGOLO, 2002).

No caso específico desta pesquisa existe uma forte integração entre o pesquisador e os sujeitos do estudo, visto que as duas categorias compartilham o mesmo nicho de trabalho.

Os sujeitos da pesquisa foram indivíduos predominantemente do gênero masculino, com idades entre 20 e 68 anos de idade. Realizam o transporte de derivados de petróleo da base de distribuição da Petrobras Transportes, no município de Biguaçu, para toda a região da Grande Florianópolis e outras cidades do Estado de Santa Catarina. O grau de escolarização destes indivíduos perpassa os que concluíram o ensino de primeiro grau, até aqueles que não finalizaram o curso superior.

Os instrumentos alocados nesta pesquisa foram a observação direta intensiva e extensiva e o preenchimento de um questionário específico para cada participante. Durante a pesquisa os dados foram mantidos em sigilo e utilizados somente pelos integrantes da pesquisa, sendo preservada a imagem dos envolvidos e o conteúdo dos questionários.

A coleta dos dados foi realizada através um questionário préestabelecido para cada participante da pesquisa. Optou-se pela ferramenta do questionário por se tratar de uma modalidade de resposta rápida - os caminhoneiros estão em constante stress e uma das variáveis deste stress é o tempo.

O questionário foi preenchido por um grupo de 30 caminhoneiros, na primeira quinzena de outubro de 2019. O preenchimento do questionário foi individualizado. O horário não foi pré-determinado, ou seja, o caminhoneiro optava por preencher seu questionário no momento mais oportuno. No período da manhã, o caminhoneiro tem a ânsia de realizar o seu carregamento o mais rápido possível e de realizar as suas entregas. Neste período, geralmente o trabalhador não optava por preencher seu questionário. 
O questionário foi estruturado tentando abarcar uma lógica que abrangesse o maior número de dúvidas que os caminhoneiros tinham acerca do processo de trabalho e de sua aprendizagem. Estas percepções iniciais sobre o processo foram levantadas em uma série de diálogos promovidos pelo entrevistador com os caminhoneiros. Uma gama vastíssima de dúvidas foi levantada pelos participantes da pesquisa, sendo eleitas as dúvidas mais frequentes.

\section{RESULTADOS E DISCUSSÕES}

Os resultados serão apresentados com uma breve caracterização do nosso corpo amostral, centrado principalmente nos dados sociodemográficos captados na pesquisa. Os dados foram catalogados em um quadro com as principais informações pertinentes aos caminhoneiros. O levantamento dos dados foi realizado no espaço laboral dos próprios entrevistados, inserindo-se em sua rotina diária de carregamento rodoviário. Os próprios participantes da pesquisa preencheram os questionamentos ora levantados na entrevista.

A média de idade dos motoristas foi de 44 anos, o que demonstra tratarse de uma força de trabalho experiente e com determinado grau de maturidade profissional. Destaque-se que, do universo de 30 entrevistados, $66,66 \%$ tinham 40 anos ou mais.

Quanto ao nível de escolaridade, a maioria dos caminhoneiros tinha ensino de segundo grau completo. Nos questionários ficou evidenciado que os motoristas com menor idade possuíam um maior grau de instrução frente ao grupo de motoristas com maior idade. A necessidade de estudar ou de manterse atualizado foi mais frequente no grupo mais jovem. Os motoristas mais velhos alegavam que não tinham mais ânimo para o estudo ou que não conseguiam "pegar" o assunto com tanta facilidade.

O indicador "tempo na profissão" revelou uma equipe com um bom grau de maturidade com relação ao exercício da profissão. Com uma média de 19 anos de carreira, os motoristas apresentaram um perfil consolidado na execução das tarefas diárias nesta Estação de Carregamento Rodoviário.

Os resultados de pesquisa também apontaram que $53 \%$ dos entrevistados tem como principal dificuldade de aprendizagem no trabalho "seguir padrões dos processos de trabalho" e "dificuldade de interagir com a tecnologia". Se acrescentarmos a isso os $20 \%$ que apresentaram como principal dificuldade a "pressão do empregador por resultados", temos uma esmagadora maioria (73\%) de respostas concentradas em 3 dificuldades.

Quanto às possíveis soluções para a dificuldade de aprendizagem, três foram majoritariamente apontadas, com $73 \%$ das indicações. Em primeiro e expressivo lugar, a promoção de mais ciclos de capacitação (33\%); em segundo, maior atenção aos processos normatizados (23\%), e em terceiro lugar, a apresentação das normas em processos práticos (17\%). 
No quarto questionamento foi perguntado aos motoristas se "a adoção de um material didático poderia ajudá-los na promoção de seu aprendizado", obtendo-se resposta positiva dfe $100 \%$. E na definição de qual material didático seria o mais apropriado para a facilitação de seu processo de aprendizagem, outro resultado avassalador. A opção "banner com personagem em história de quadrinhos (HQ)" angariou 63\% da preferência dos participantes da pesquisa, ficando a opção "filmes curtos" em $2^{\circ}$ lugar e em terceiro a opção "Material escrito", com $13 \%$.

Tal resultado foi extremamente revelador. O forte indicativo foi de que, em seu processo de trabalho com jornadas exaustivas e a necessidade de muita atenção, tais profissionais não queriam perder tempo com leituras, conteúdos por aplicativo ou exibição de filmes. Preferiam algo mais objetivo e com o qual se identificassem.

\subsection{PRODUTO EDUCACIONAL}

O recurso educacional proposto foi a construção de um banner digital ilustrado com uma temática direcionada para os principais conceitos do processo de trabalho inerente à prática laboral dos sujeitos da pesquisa. Assim, criou-se a figura de um avatar, apelidado de Tião, que trazia mensagens importantes para os processos de aprendizagem dos caminhoneiros.

Neste material alocamos os desafios e as possíveis soluções enfrentadas pelos sujeitos no processo de aquisição de conhecimentos no seu ambiente de trabalho, com uma linguagem simples, objetiva e esclarecedora. A diagramação visual do banner foi rica em imagens que retratassem 0 cotidiano laboral do público-alvo, preferencialmente ilustrada na forma de quadrinhos.

Bacelar et al., (2009) nos remetem à ideia de que o uso de ilustrações permite aos sujeitos da pesquisa uma maior aproximação com sua realidade, a visualização de todos os detalhes envolvidos no processo de ensinoaprendizagem, bem como uma maior percepção dos processos laborais que ocorrem de forma muito rápida ou muito lenta.

Ainda para a mesma autora, a definição de uma cartilha está diretamente vinculada a qualquer padrão de comportamento que possa ser retratado através de ilustrações e que o conteúdo dela deva espelhar a realidade vivida pelos sujeitos da pesquisa.

Destarte, em um estudo realizado por Godoy; Ferreira (2008) apontouse uma série de sintomas e sinais encontrados em um grupo de caminhoneiros estudados. Entre estes sintomas destacaram-se: sonolência, fadiga, irritabilidade, nível de atenção diminuídos, reflexos diminuídos, solidão, distúrbios gastrointestinais e raciocínio difícil. 
O recurso educacional aplicado possibilitou uma maior assimilação dos conhecimentos do mundo do trabalho, atacando principalmente o último sintoma referenciado na pesquisa de (GODOY; FERREIRA, 2008), 0 "raciocínio difícil". O raciocínio eficaz ao longo da jornada de trabalho tende a diminuir por parte dos sujeitos da pesquisa. A atenção focada no processo tende a decrescer principalmente próximo ao horário do almoço e do horário da última entrega do dia.

Segundo levantamento feito pela Confederação Nacional dos Caminhoneiros no ano de 2019, a média de idade destes trabalhadores oscila na casa de 44,8 anos, com forte prevalência do sexo masculino (99,7\%), sendo que o grau de instrução apresentado varia entre aqueles que não são alfabetizados $(0,8 \%)$ até aqueles que possuem uma pós graduação completa $(0,1 \%)$, ficando a grande maioria $(27,7 \%)$ entre aqueles que concluíram 0 segundo grau colegial. (CNT, 2019).

Em nosso levantamento sociodemográfico constatamos algumas semelhanças em relação aos dados da CNT. A média de idade de nossa pesquisa ficou em 44 anos, faixa etária muito próxima da apontada pela pesquisa da CNT, e o grau de instrução dos entrevistados em nossa pesquisa, majoritariamente, enquadrou-se no grupo dos que concluíram o segundo grau.

$O$ recurso educacional aplicado em nosso estudo abarcou todos os graus de escolaridade dos entrevistados. E um material extremamente técnico ou que utilizasse uma linguagem potencialmente culta não alcançaria os resultados esperados: não haveria a assimilação do conteúdo e nem o debate sobre a temática apresentada.

Na visão de HUG (2005), o Microlearning é um tipo de ferramenta de aprendizagem com características específicas, como o breve tempo de exposição dos conteúdos, com mensagens didáticas curtas e de fácil absorção por parte dos alunos, que obtém pequenas cápsulas de conhecimento durante a exposição das mensagens. São pílulas de conhecimento dosadas de forma espaçada e de maneira contínua.

Este tipo de técnica foi aplicado no material didático que elaboramos e na sua aplicação em si. Uma temática extremamente variada foi exposta no banner digital, em um programa de aplicação de um mês (segunda quinzena de outubro de 2019 até a primeira quinzena de novembro de 2019).

A história em quadrinhos (HQ) moderna advém do início da intelectualização do homem enquanto ser pensante. As inscrições rupestres feitas pelos nossos ancestrais corroboram a tese de que a transmissão de conhecimento poderia se dar através de desenhos e por uma narrativa que comportasse uma determinada história que abarcasse principalmente 0 aspecto visual da obra. Nos dias atuais as histórias em quadrinho apresentam características de imagens e de escrita, podendo até mesmo vislumbrar elementos ligados a figuras de linguagem, como as onomatopeias, que são palavras que procuram reproduzir sons ou ruídos. (GIOVANETTI, 2005). 
Todos estes elementos da história em quadrinhos (HQ) se enquadram no perfil de aprendizagem dos nossos sujeitos de pesquisa, visto que teríamos duas vertentes para o seu aprendizado, que comportam o aspecto visual e o escrito.

As histórias em quadrinhos podem ser interpretadas como um caminho para uma leitura de caráter mais formal, visto que o contato de todos os públicos com este tipo de material proporciona uma motivação primária para o enfrentamento de textos mais complexos e variados. Estes escritos ultrapassam a fronteira do mundo do trabalho e alcançam vários aspectos de aprendizagem da vida do indivíduo. (SANTOS, 2003).

A versão final do produto educacional, com a visualização do avatar denominado Tião, seguiu a proposta apresentada abaixo.

FIGURA 1: ilustração com os Recurso Educacional - Capa

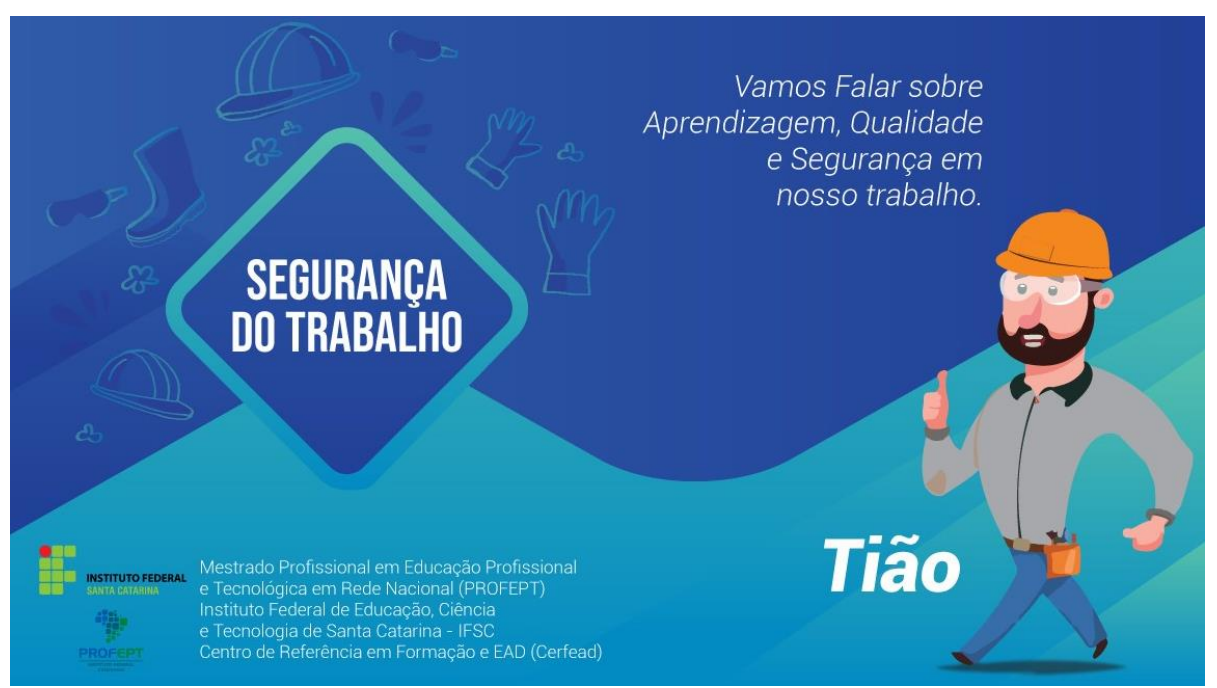

Fonte: Do autor (2020).

Na capa houve a apresentação do personagem em si, a estruturação do avatar, simbolizado na figura de um caminhoneiro padrão. A caracterização do avatar seguiu a tipologia real do caminhoneiro em seu trabalho. $O$ uso dos EPI's (capacete, óculos, camisa de manga comprida e botas de segurança) foi minuciosamente pensando, pois o personagem do processo de aprendizagem deveria refletir o modelo adequado de vestimenta e EPI's no mundo real.

O uso do capacete permite que o caminhoneiro proteja a região da cabeça contra possíveis choques, os óculos permitem a segurança do portador contra respingos de combustíveis oriundos do processo de carregamento, o uniforme de manga comprida tem a função de proteger o trabalhador em caso de incêndio e de queimaduras. Nota-se que o tecido, o tipo de fibra usado nos uniformes, não pode ter uma constituição sintética e sim uma constituição de Vol. 2 (2020) 
base vegetal. Em qualquer caso de sinistro (incêndio na plataforma), o uniforme de manga comprida permite a proteção dos braços do trabalhador.

Por ser de um tecido vegetal (algodão), ele fornece a dita proteção e não fica colado na pele do trabalhador, facilitando o tratamento após um possível incêndio.

Nota-se que o avatar também possui uma pochete onde são guardados os demais EPI's utilizados no seu processo de trabalho, tais como luvas e protetores auriculares.

$\mathrm{Na}$ capa também temos os três eixos temáticos norteadores de nosso produto educacional, quais sejam, a aprendizagem, a qualidade e a segurança no ambiente de trabalho. Optou-se por esta temática na tentativa de elaborar um produto educacional vivo, orgânico e essencialmente funcional; as mensagens curtas, baseadas na tipologia de aprendizagem tipo Microlearning, se ajustaram perfeitamente na rotina dos caminhoneiros.

O banner digital ficou hospedado na mesma tela em que os motoristas viam a sua programação diária de carregamento. Ou seja, o motorista, em algum momento do dia, "beberia" das pílulas do conhecimento proporcionadas pelo banner digital. A programação diária do carregamento saí conforme a demanda de combustíveis da região de atendimento: o motorista, em média, tem uma programação que comporta de uma a quatro viagens por dia.

A visualização desta programação ocorre em uma tela de 50 polegadas, instalada na sala de espera dos caminhoneiros na Estação de Carregamento Rodoviário de Biguaçu. Neste local, os trabalhadores observam e estudam sua programação de entrega, tomam um café e se preparam para a etapa de carregamento. Utilizamos esta etapa para a aplicação do banner digital, nosso recurso educacional aplicado.

No primeiro slide de conteúdo trabalhamos com uma proposta voltada para uma mensagem de cuidado e seguimento dos padrões de segurança e do próprio trabalho com segurança. Macedo e Bianchi (2019), em seu estudo, nos relatam que o stress provoca alterações fisiológicas significativas nos caminhoneiros, afetando a percepção dos perigos envolvidos no processo de trabalho e no próprio trânsito.

Nota-se que, em nosso estudo, trabalhamos em um ambiente de alto grau de periculosidade, com carregamento médio que ultrapassa 70 caminhões-tanque por dia, sendo que estes carregam em média 30 mil litros de combustível por viagem ou entrega. O produto transportado é de alto grau de periculosidade quando afeta de maneira direta ou indireta as pessoas, o meio ambiente e a região que o circunvizinha. Assim, combustíveis inflamáveis ou produtos explosivos podem ser enquadrados nesta categoria. (FERREIRA, 2003).

No terceiro slide do banner digital nos centramos na propagação da ideia da importância do conhecimento e dos novos avanços tecnológicos nos processos de trabalho. De acordo com nossa pesquisa, a média de idade dos 
trabalhadores entrevistados foi de 44 anos (destaque-se que existem, no universo de nossa pesquisa, caminhoneiros com idade superior a 65 anos). A inovação tecnológica é algo rotineiro dentro de uma plataforma de carregamento rodoviário.

Em um estudo de Buaes (2004) foi constatado que determinados indivíduos apresentam uma certa oposição em adquirir novos conhecimentos, ficando presos aos conhecimentos antigos, tendo medo em aprender algo novo. A instalação de um novo equipamento reflete este comportamento nos próprios caminhoneiros: tudo que é novo é extremamente criticado no ambiente de trabalho. Por isso, buscou-se, através da mensagem do banner, promover uma maior conscientização sobre a importância do aprendizado e do próprio ato de aprender dentro do contexto laboral.

No quarto slide de nosso recurso educacional, trabalhamos com um enfoque baseado na mensagem "Trabalhe com calma e com muita segurança! Evite acidentes, volte para sua família inteiro e com muita saúde! Valorize a vida, valorize o seu ambiente de trabalho! A pressa sempre foi inimiga da perfeição. Lembre-se disso!'

Pereira et al. (2015) nos trazem que o ritmo de trabalho extenuante dos caminhoneiros, a rotina dos horários de entregas, de manter a carga segura e de preservar a integridade material do veículo de transporte (cujo dono geralmente é o empregador) e a exposição aos riscos do ambiente de trabalho são fatores que potencializam a ocorrência de acidentes nos locais de trabalho.

No quinto slide, trabalhamos a temática referente à concentração nos ambientes de trabalho. Em média, um motorista de caminhão-tanque consegue carregar de seu veículo em 20 minutos. Neste tempo em que o caminhoneiro está na plataforma, diversas variáveis do processo têm que ser monitoradas, tais como a vazão de carregamento e o volume carregado. A concentração tem que ser redobrada durante esta fase crítica do trabalho. A frase "Com o Tião não tem massagem!" reportou-se a uma expressão típica dos caminhoneiros de Biguaçu (SC), um jargão no sentido de que não haverá moleza na execução da tarefa. O vocabulário dos próprios caminhoneiros foi incorporado no preparo e na execução do banner digital.

Na lâmina seguinte do banner digital, enfatizamos a participação dos trabalhadores em cursos de capacitação dentro da própria Transpetro. Da Silva (2019) apud Cataldi (2002) relata que as empresas modernas têm cada vez mais incentivado a capacitação dos seus colaboradores em ambientes interna corporis, investindo no bem-estar dos trabalhadores e traçando um novo perfil organizacional, o que reflete na saúde e na estabilidade emocional do trabalhador. Assim, a capacitação fora dos ambientes formais de aprendizagem foi um dos destaques do recurso educacional produzido.

Na sequência do nosso produto educacional, enfatizamos a importância de seguir os padrões normatizados da empresa, para preservar a saúde e a segurança do próprio trabalhador, enfatizando a importância de se trabalhar com calma, sempre portando os EPI's necessários para a execução da tarefa. 
Na oitava lâmina do recurso educacional, proposto trabalhamos com a questão da importância da solidariedade no aprendizado em uma área industrial. Nosso público-alvo tem um alto grau de rotatividade no trabalho em si: novos caminhoneiros são frequentemente recrutados para atender a variações na demanda por consumo de combustíveis.

Observou-se em campo que os trabalhadores mais velhos tutelam 0 aprendizado dos mais novos, em uma espécie de troca constante de conhecimentos; a amizade no trabalho tem reflexos diretos no processo de aprendizagem do indivíduo.

Nesta linha de pensamento, temos que os próprios indivíduos se adaptam na aprendizagem, frente a uma dificuldade inerente do processo de trabalho. Pressionados muitas vezes pela competição do mercado, os trabalhadores apoiam-se mutuamente na busca da resolução de problemas imediatos de aprendizagem (GIMENEZ, 2010, citado por SOUZA, 2016).

Paralelamente a isso, temos o conceito de andragogia, em que um público adulto frente a uma situação-problema específica desenvolve soluções para esta demanda social imediata: os trabalhadores se adequam à situaçãoproblema, ocorrendo o aprendizado nesta etapa, neste caminhar solidário. (GUEDEZ; SILVA, 2020). Uma situação-problema na plataforma de carregamento, geralmente vinculada a alguma necessidade de aprendizado, gera a cooperação dos pares, enredando uma teia de ajuda mútua, constituindo uma autêntica comunidade de práticas.

Na nona parte do banner digital, abordamos, novamente, a segurança dos processos de trabalho, focando no uso adequado de EPI's tais como bota, capacete, cinto de segurança tipo paraquedista, óculos de segurança, uniforme $100 \%$ em algodão natural, bem como o uso de luvas. O incentivo ao uso de EPI's de uso obrigatório foi uma parte importante do recurso educacional, pois os caminhoneiros apresentam resistência em utilizar e portar seus equipamentos de proteção individual, notadamente os óculos e as luvas. Mas por trabalhar em uma área de alto risco, com a presença constante de gases inflamáveis, o uso destes equipamentos tem caráter obrigatório por força das normas internas da companhia e por força da própria lei em si.

A interação entre o avatar Tião e público-alvo focalizou a questão do uso correto e consciente dos EPIs na área industrial. Buscava-se também, que o trabalhador envolvido nos processos de trabalho interna corporis, estendesse este cuidado, no uso de EPI's, não só focalizando o lado profissional, mas agregando um valor de cuidado no seu lado pessoal. Se o motorista utiliza uma luva no processo de carregamento, poderia utilizar este mesmo tipo de EPI para a troca de um pneu furado, por exemplo, no cunho de sua vida pessoal.

Nos dois slides seguintes de nosso recurso educacional, enfatizamos a legislação de trânsito e os perigos da ingestão da bebida alcoólica ao volante e do uso do celular na direção do veículo. A organização do trabalho e dos processos industriais tem um peso importante na ocorrência ou não de acidentes de trabalho. Segundo Moraes; Cunha; Andrade (2019), os acidentes 
de trabalho geralmente ocorrem com os iniciantes da profissão, com o público mais jovem, mais vulnerável ao fator stress. E de acordo com um levantamento feito pela Policia Rodoviária Federal para o ano de 2019, as principais causas de acidentes nas rodovias federais brasileiras estavam atreladas ao descuido em conduzir o veículo (37,0\%), violação da legislação de trânsito (12,0\%), velocidade acima da permitida $(9,0 \%)$ e ingestão de bebida alcoólica $(8,0 \%)$. (PRF, 2019).

A manutenção veicular também foi tratada no recurso educacional, por se constituir em um dos fatores que ocasionam acidentes de trânsito. Quando entra na área industrial, o caminhoneiro tem que preencher um check-list onde são conferidos o estado geral do caminhão, estado dos pneus, válvulas de alinhamento para o tanque, sensores anti-transbordamento, estado da lataria, condições do para-brisa, entre tantos outros. Se ocorrer qualquer desvio nestes itens de checagem, o caminhoneiro fica proibido de realizar o carregamento de combustível até que a não conformidade seja efetivamente tratada e o checklist é visto como uma ferramenta imposta pela empresa, com caráter eminentemente punitivo. O recurso educacional procurou fechar esta lacuna, no sentido de esclarecer estes motoristas para manterem seus caminhões em bom estado de conservação, atrelando este fator à segurança e à saúde no ambiente de trabalho e dos próprios caminhoneiros.

No décimo terceiro e no décimo quarto slides, abordamos a manutenção preventiva e corretiva dos caminhões-tanques que carregam na base da Transpetro em Biguaçu (SC) e a importância da alimentação saudável para o caminhoneiro. Segundo estudo elaborado por Pinto; Bueno (2019), houve um aumento do número de doenças crônicas não transmissíveis entre a classe de motoristas, com preponderância do diabetes, da obesidade e da hipertensão arterial. Entre as principais causas destas enfermidades constata-se o longo período que os caminhoneiros ficam em uma única posição (sentada) e o grande consumo de lanches com alta dose de composição energética.

Os fatores externos que proporcionam a opção forçada por este estilo de vida estão ligados à má alimentação, à pressão do empregador por resultados (mais entregas de combustível em menos tempo) e ao stress provocado pelo trânsito.

\section{CONSIDERAÇÕES FINAIS}

A capacitação de motoristas de caminhões-tanque em ambientes não formais no sistema Petrobras do Estado de Santa Catarina (SC) representou um grande desafio em nível pessoal, acadêmico e profissional. O estudo in loco de uma comunidade de prática apresentou nuances extremamente sensíveis na visão do pesquisador.

Esta comunidade de prática se insere em um ambiente de natureza industrial, com graus de periculosidade diversos, em que processos de aprendizagem são introduzidos e ressignificados de maneira quase que diária. Vol. 2 (2020) 
Um problema técnico, a falta de capacidade de carregar um caminhão, a dificuldade de interagir com a tecnologia, que muda de maneira frequente, ensejam nesta comunidade um conceito de união e solidariedade. Os caminhoneiros mais experientes se inserem neste contexto ajudando os menos experientes na aquisição de conhecimentos típicos do processo de trabalho.

Esta transmissão de conhecimentos se dá basicamente de algumas maneiras, tais como: a transmissão verbal do que deve ser feito e aprendido, a transmissão de conhecimento pelo fazer, demonstrando na prática as nuances do desafio a ser superado e, por fim, através de cursos de capacitação interna da própria empresa.

O processo de trabalho em uma indústria petrolífera apresenta algumas dificuldades bem acentuadas. De um lado, temos um corpo técnico altamente treinado e especializado, que passa por constantes planos de capacitação e aperfeiçoamento, seja utilizando cursos presenciais em grandes institutos de ensino, seja através da qualificação via EAD, ministrada por profissionais que também trabalham na área industrial.

Do outro lado, temos trabalhadores que ingressam nos processos de trabalho deste complexo mundo industrial sem ter qualquer tipo de conhecimento técnico específico para a execução das tarefas. Na maioria das vezes são pessoas que adquiriram o conhecimento laborativo através do ato de fazer. Este conhecimento adquirido deve ser sempre valorizado pela equipe que os monitora e que tem o dito conhecimento formal. Isto porque várias soluções de natureza técnica nasceram deste conhecimento produzido por aqueles que operacionalizam o processo, que aprendem pelo fazer, que não tiveram a oportunidade de frequentar um ambiente formal de aprendizagem, mas que oferecem soluções sutis e engenhosas para os mais diversos grupos de problemas enfrentados em um processo industrial.

Destaca-se que existe um enorme desafio em unir estes dois mundos, estes dois quadrantes que geram conhecimento: o daqueles que produzem 0 conhecimento no cotidiano laboral com o conhecimento que é produzido pela academia. A união das formas de produzir conhecimento, independentemente de suas fontes, deve ser constantemente valorizada. O trabalho por si só produz - e muito - conhecimento!

$\mathrm{Na}$ elaboração desta pesquisa, o conceito de trabalho foi se transmutando na visão do pesquisador: de um simples ato laborativo, transformou-se em uma forma de aprender e difundir conhecimentos. Em vários momentos da pesquisa, quando estava inserido na plataforma de carregamento rodoviário, pude observar uma comunidade de prática que se estrutura de maneira fantástica. Do desembarcar do caminhão até a finalização do carregamento, existem detalhes que deveriam ser estudados com mais cautela, com um olhar diferenciado por parte da academia.

A título de exemplo, cito o caminhoneiro que ao carregar seu caminhão, limpava com extremo denodo todos os bocais onde seriam inseridos os braços de carregamento de produtos inflamáveis. Tais braços de carregamento 
possuem anéis de vedação, confeccionados em borracha sintética, que têm a função de estancar vazamentos dos bicos de acoplamento. Quando o caminhoneiro trafega com seu veículo, partículas sólidas se acumulam nos bocais. Ao chegar na plataforma, o caminhoneiro insere o braço nos bocais de carregamento já contaminados com poeira, o que ocasiona a deterioração mecânica dos anéis de vedação, gerando mais custos operacionais no processo de carregamento. Em síntese: ao limpar os bocais de seu veículo, o caminhoneiro produz um conhecimento através do seu ato laborativo, ajudando na manutenção e continuidade dos processos de trabalho dentro da empresa.

Cita-se outro exemplo desta comunidade de prática: cada caminhoneiro recebe uma programação de carregamento de combustíveis que vem impressa em um ticket. Muitos, por exercerem a função por bastante tempo, têm um grau de confiança muito elevado, o que facilita a ocorrência de acidentes vinculados a transbordamento de combustíveis. Para evitar que isso prosseguisse, um deles montou um sistema com imãs em uma superfície metálica, possibilitando que o caminhoneiro leia a sua programação afixada, estando com as mãos livres para dar continuidade ao seu trabalho.

O recurso educacional do avatar, do personagem Tião, foi estruturado tomando como base alguns pilares teóricos, com assuntos que propunham o conceito de aprendizagem, de segurança do trabalho e com cuidados na saúde do próprio caminhoneiro.

Alicerçado em um conceito baseado na metodologia do Microlearning, pequenas doses de conhecimento eram inseridas na rotina de trabalho dos motoristas, no intuito de que tais conhecimentos fosses assimilados e postos em prática pelos trabalhadores.

O banner digital com o personagem Tião foi moldado com base nos resultados da pesquisa. Em cada slide apresentado no ambiente interno da Transpetro em Biguaçu para os motoristas de caminhões-tanque foi levantado algum tipo de necessidade ou dificuldade de aprendizagem que eles tinham em relação aos seus processos de aprendizagem. Do início do programa até o presente momento houve uma significativa diminuição de incidentes e acidentes na plataforma de carregamento, demonstrando que o recurso educacional aplicado se tornou orgânico e vivo na organização, contribuindo para os quesitos de aprendizagem, segurança e saúde dos trabalhadores.

Os resultados exibidos nesta pesquisa poderão contribuir para a expansão do programa em outras unidades da Petrobras espalhadas no território nacional, reverberando os resultados alcançados em Santa Catarina para outros Estados. A particularização do avatar não precisará ter um caráter homogêneo para todas as regiões, sendo que modificações poderão ser inseridas valorizando aspectos sociais da região comtemplada com o programa. 


\section{REFERÊNCIAS}

ALVES, Marissol Mello; ANDRÉ, Claudio Fernando. Modelo 702010 e o microlearning: alternativas para problemas modernos na educao corporativa.

Teccogs: Revista Digital de Tecnologias Cognitivas, TIDD | PUC-SP, So Paulo, n. 16, p. 39-53, jul-dez. 2018.

BUAES, Caroline Stumpf. Envelhecimento e educação: em foco a aprendizagem de trabalhadores mais velhos. Estudos Interdisciplinares sobre o Envelhecimento, v. 6, 2004.

CNT, CONFEDERAÇÃO NACIONAL DO TRANSPORTE. Perfil dos caminhoneiros 2019: Disponível em: https://www.cnt.org.br/agencia$\mathrm{cnt} /$ pesquisa-cnt-perfil-caminhoneiros-brasil-2019. Acesso em: 23 de jun. de 2019.

SILVA, Priscila Morais. Estudo de variáveis que permeiam o ambiente de trabalho de uma fábrica de embalagens e seus impactos na produtividade. Trabalhos de Conclusão de Curso, UNIFACIG, 2019.

Disponível em:

http://pensaracademico.unifacig.edu.br/index.php/repositoriotcc/article/view/17 76/1389. Acesso em: 20 mar. 2019.

FERREIRA, Carlos Eugenio de Carvalho. Acidentes com motoristas no transporte rodoviário de produtos perigosos. São Paulo em Perspectiva, v. 17, n. 2, p. 68-80, 2003.

GÂNDARA, Guilherme; DA CRUZ, Poliano Bastos. A satisfação no trabalho como antecedente da produtividade no transporte rodoviário de cargas. Refas-Revista Fatec Zona Sul, v. 5, n. 4, p. 38-49, 2019.

GIL, Antônio Carlos. Métodos e técnicas de pesquisa social. 5. ed. São Paulo: Atlas, 1999.

GIMENEZ, Adriane Barbosa. Estratégias de aprendizagem no trabalho: Uma prática exigida pela atualidade. Gestão e Sociedade, v. 14, n. 37, p. 33063337, 2020.

GIOVANETTI, Aparecida Richena. A vida em tiras. Centro Universitário das Faculdades Associadas de Ensino - FAE. Disponível em http://www.unifaesj.edu.br/Noticias/n180.html. Acesso em 13 de junho de 2019.

GOHN, Maria da Glória. Educação não formal no campo das artes. São Paulo: Cortez Editora, 2015.

GOHN, Maria da Glória. Educação não-formal, participação da sociedade civil e estruturas colegiadas nas escolas. Rio de Janeiro: Revista EnsaioAvaliação e Políticas Públicas em Educação, v. 14, n. 50, p. 11-25, 2006.

HUG, Theo. Micro Learning and Narration. Exploring possibilities of utilization of narrations and storytelling for the designing of" micro units" and didactical micro-learning arrangements. In: FOURTH MEDIA IN Vol. 2 (2020) 
TRANSITION CONFERENCE. 2005.

MORAES, Thiago Drumond; CUNHA, Kamilla Rocha; DE ANDRADE, Alexsandro Luiz. Percepção de caminhoneiros sobre fatores associados à ocorrência de acidentes de trabalho. Revista de psicología (Santiago), v. 28, n. 1, p. 28-41, 2019.

PEREIRA, Francisco Gilberto Fernandes et al. Relação entre processo de trabalho e saúde de caminhoneiros. Revista Brasileira em Promoção da Saúde, v. 27, n. 4, p. 462-469, 2015.

SANTOS, R. E. A História em Quadrinhos na Sala de Aula. INTERCOM Sociedade Brasileira de Estudos Interdisciplinares da Comunicação.In: CONGRESSO BRASILEIRO DE CIÊNCIAS DA COMUNICAÇÃO. 26. Belo Horizonte, MG. 2003 Anais.... Belo Horizonte, MG. 2003

SILVA, Marise Borba de; GRIGOLO, Tânia Maris. Metodologia para iniciação cientifica à prática da pesquisa e da extensão II. Caderno Pedagógico. Florianópolis: Udesc, 2002.

SOUZA, Antonio Carlos de; FIALHO, Francisco Antonio Pereira; OTANI, Nilo. TCC: métodos e técnicas. Florianópolis: Visualbooks, 2007.

SOUZA, Maria LH de. Avaliação da efetividade dos principais cursos FIC Pronatec do Instituto Federal de Santa Catarina: benchmarking com cursos técnicos de longa duração. 2016.

TRANSPETRO. Petrobras Transportes. Disponível em:

http://portal.transpetro.com.br/intr/appmanager/portallntranet/DDT?_nfpb=true \&_nfls=false\&_pageLabel=paginaModulo_page\&formConteudo:codigo $=8495$. Acesso em: 8 mar. 2019.

VIEIRA PINTO, Álvaro. O Conceito de Tecnologia, Rio de Janeiro: Contraponto, 2008.

WENGER, Etienne C.; SNYDER, William M. Communities of practice: The organizational frontier. Harvard business review, v. 78, n. 1, p. 139-146, 2000.

WENGER, Etienne. Communities of practice: A brief introduction. 2011. 